\title{
Imagery of a moving object: the role of occipital cortex and human MT/V5+
}

Citation for published version (APA):

Kaas, A. L., Weigelt, S., Roebroeck, A. F., Kohler, A., \& Muckli, L. (2010). Imagery of a moving object: the role of occipital cortex and human MT/V5+. Neuroimage, 49(1), 794-804.

https://doi.org/10.1016/j.neuroimage.2009.07.055

Document status and date:

Published: 01/01/2010

DOI:

10.1016/j.neuroimage.2009.07.055

Document Version:

Publisher's PDF, also known as Version of record

Document license:

Taverne

Please check the document version of this publication:

- A submitted manuscript is the version of the article upon submission and before peer-review. There can be important differences between the submitted version and the official published version of record.

People interested in the research are advised to contact the author for the final version of the publication, or visit the DOI to the publisher's website.

- The final author version and the galley proof are versions of the publication after peer review.

- The final published version features the final layout of the paper including the volume, issue and page numbers.

Link to publication

\footnotetext{
General rights rights.

- You may freely distribute the URL identifying the publication in the public portal. please follow below link for the End User Agreement:

www.umlib.nl/taverne-license

Take down policy

If you believe that this document breaches copyright please contact us at:

repository@maastrichtuniversity.nl

providing details and we will investigate your claim.
}

Copyright and moral rights for the publications made accessible in the public portal are retained by the authors and/or other copyright owners and it is a condition of accessing publications that users recognise and abide by the legal requirements associated with these

- Users may download and print one copy of any publication from the public portal for the purpose of private study or research.

- You may not further distribute the material or use it for any profit-making activity or commercial gain

If the publication is distributed under the terms of Article $25 \mathrm{fa}$ of the Dutch Copyright Act, indicated by the "Taverne" license above, 


\title{
Imagery of a moving object: The role of occipital cortex and human MT/V5+
}

\author{
Amanda Kaas a,b,c,*, Sarah Weigelt ${ }^{\text {a,b }}$, Alard Roebroeck ${ }^{c}$, Axel Kohler ${ }^{\text {a,b }}$, Lars Muckli ${ }^{\text {a,b,d }}$ \\ a Department of Neurophysiology, Max Planck Institute for Brain Research, Deutschordenstr. 46, D-60528 Frankfurt am Main, Germany \\ b Brain Imaging Center Frankfurt, Schleusenweg 2-16, D-60528 Frankfurt am Main, Germany \\ c Department of Cognitive Neuroscience, Faculty of Psychology E Neuroscience, Maastricht University, Postbus 616, 6200 MD Maastricht, The Netherlands \\ ' Center for Cognitive Neuroimaging CCNi, Department of Psychology, University of Glasgow, 58 Hillhead Street, Glasgow G12 8QB, UK
}

\section{A R T I C L E I N F O}

\section{Article history:}

Received 17 April 2009

Revised 10 July 2009

Accepted 22 July 2009

Available online 29 July 2009

\section{Keywords}

Human

fMRI

Connectivity

Parietal

Attention

Spatial transformations

\begin{abstract}
A B S T R A C T
Visual imagery - similar to visual perception - activates feature-specific and category-specific visual areas. This is frequently observed in experiments where the instruction is to imagine stimuli that have been shown immediately before the imagery task. Hence, feature-specific activation could be related to the short-term memory retrieval of previously presented sensory information.

Here, we investigated mental imagery of stimuli that subjects had not seen before, eliminating the effects of short-term memory. We recorded brain activation using fMRI while subjects performed a behaviourally controlled guided imagery task in predefined retinotopic coordinates to optimize sensitivity in early visual areas.

Whole brain analyses revealed activation in a parieto-frontal network and lateral-occipital cortex. Region of interest (ROI) based analyses showed activation in left hMT/V5+. Granger causality mapping taking left hMT/V5 + as source revealed an imagery-specific directed influence from the left inferior parietal lobule (IPL). Interestingly, we observed a negative BOLD response in V1-3 during imagery, modulated by the retinotopic location of the imagined motion trace.

Our results indicate that rule-based motion imagery can activate higher-order visual areas involved in motion perception, with a role for top-down directed influences originating in IPL. Lower-order visual areas (V1, V2 and V3) were down-regulated during this type of imagery, possibly reflecting inhibition to avoid visual input from interfering with the imagery construction. This suggests that the activation in early visual areas observed in previous studies might be related to short- or long-term memory retrieval of specific sensory experiences.
\end{abstract}

(c) 2009 Elsevier Inc. All rights reserved.

\section{Introduction}

Mental imagery is a perceptual experience occurring in the absence of appropriate external stimulation. Evidence has accumulated favoring the view that it is associated with activation in a cortical network similar to that involved in actual perception, including modality-specific sensory brain areas (Barsalou, 2008; Kosslyn and Thompson, 2003). However, the conditions determining which exact level of the sensory hierarchy is involved in a specific imagery task are still unclear.

Higher-order visual areas show responses to both perceived and imagined stimuli from specific categories of visual information (Farah, 1989). For instance, imagined faces activated the fusiform gyrus (Ishai et al., 2000), imagined places the parahippocampal place area (O'Craven and Kanwisher, 2000) and imagined motion

\footnotetext{
* Corresponding author. Department of Cognitive Neuroscience, Faculty of Psychology \& Neuroscience, Maastricht University, Postbus 616, 6200 MD Maastricht, The Netherlands. Fax: +31433884125.

E-mail address: a.kaas@maastrichtuniversity.nl (A. Kaas).
}

hMT/V5+ (Goebel et al., 1998). It has been suggested that this activation in temporo-occipital cortex results from a top-down influence from fronto-parietal cortex (Goebel et al., 1998; Mechelli et al., 2004).

Mixed evidence exists on the role of lower-tier visual areas, such as primary visual cortex (Kosslyn and Thompson, 2003; Mellet et al., 1998). A meta-analysis concluded that the chances to find these areas are highest during nonspatial imagery tasks with a high level of pictorial detail (Kosslyn and Thompson, 2003). But since imagery of a moving object combines a pictorial component with spatial updating of the imagined scene, the prediction for this type of mental simulation is not clear-cut.

Only few studies explicitly set out to investigate the neural correlates of imagined motion, but it has been implicitly studied in the context of mental rotation and mental tracking (Culham et al., 1998; Schicke et al., 2006). Studies on mental rotation reported both areas near putative hMT/V5+ (Cohen et al., 1996) and V1 (Podzebenko et al., 2005). Presumed hMT/V5+ and retinotopically specific activation in early visual cortex was also found when subjects mentally reproduced rotating flickering checkerboard wedges (Slotnick et al., 2005). A similar pattern of activation in 
putative hMT/V5+, V3 and V2, but not V1, was found in a study where subjects mentally reproduced previously presented flowfield stimuli (Goebel et al., 1998).

The evidence on the involvement of early visual regions and hMT/V5+ during re-enactment of visual motion is inconclusive, because the mental image was produced by retrieval of a previously presented stimulus from short-term memory. Memory retrieval has also been associated with (re-)activation of modality-specific sensory brain areas (Barsalou, 2008). Memory related re-activation has been reported in visual category-specific cortex like hMT/V5+ (Bisley et al., 2004; Pasternak and Greenlee, 2005) as well as the parahippocampal place area and fusiform face area (Ranganath et al., 2004; Sala et al., 2003). Early visual cortex retained specific information about visual features held in working memory when no physical stimulus was present (Harrison and Tong, 2009), and showed increased activation to previously presented visual stimuli (Slotnick, 2004; Slotnick and Schacter, 2004, 2006). Finally, mental imagery based on short-term memory has been found to induce stronger visual cortex activation than imagery based on long-term memory (Ishai et al., 2002).

Here, we investigate the role of category-specific and early visual regions in mental imagery of a moving stimulus which is strictly based on rules and general sensory experience stored in long-term memory. The experimental design excluded any confounding influence of perceptual processes or short-term memory. Subjects saw a static display only and imagined retinotopically specific motion that they had not been exposed to previously. This purer version of a motion imagery experiment was combined with separate retinotopic and hMT/V5+ localizer experiments to investigate the contributions of different levels of the visual hierarchy to this type of sensory re-enactment. In addition, we set out to explore the causal influences on the activated visual regions with Granger causality mapping (GCM).

\section{Materials and methods}

Subjects

Thirteen healthy volunteers ( 8 women, $20-34$ yrs) were recruited at the University of Frankfurt and the Max Planck Institute for Brain Research. Data from one male subject had to be discarded due to failure to hold fixation (see eyetracking section). Prior to the experiment the subjects gave written informed consent to the procedure which was approved by the local ethics committee of the medical faculty of the University of Frankfurt. Before scanning, they took part in a 30 min training session for the Imagined Motion (IM) task. The training session consisted of four short runs. In the first three runs, subjects performed each condition of the imagery tasks and the auditory control task in isolation. In the fourth run, all tasks conditions were mixed, as in the actual fMRI experiment.

\section{Imagery experiment}

\section{Stimuli}

For the imagined motion experiment, auditory stimuli and a static visual display (Fig. 1) were created in the Presentation software package (version 10.3, Neurobehavioral Systems Inc., Albany CA, USA; nbs.neuro-bs.com). The visual background consisted of a black rectangle ( $19.9^{\circ}$ by $15.3^{\circ}$ visual angle) surrounded by gray trapezoids, creating a 3D impression. The center of the rectangular plane contained a white cross with a faint gray circle around it (radius: $5.3^{\circ}$ visual angle). At $135^{\circ}$ in the circle's upper left quadrant, a blue ball (diameter: $0.7^{\circ}$ visual angle) was shown over a white bar (length: $1.5^{\circ}$ visual angle) with two short gray bars (length: $0.7^{\circ}$ visual angle) to the ball's left and right (offset of $33.75^{\circ}$ ). On the circle's lower right quadrant, a white bar was projected at $-45^{\circ}$, with two gray squares (height: $0.7^{\circ}$ visual angle) to its left and right (offset of $33.75^{\circ}$ ).

\section{a. Physical events (equal across conditions)}

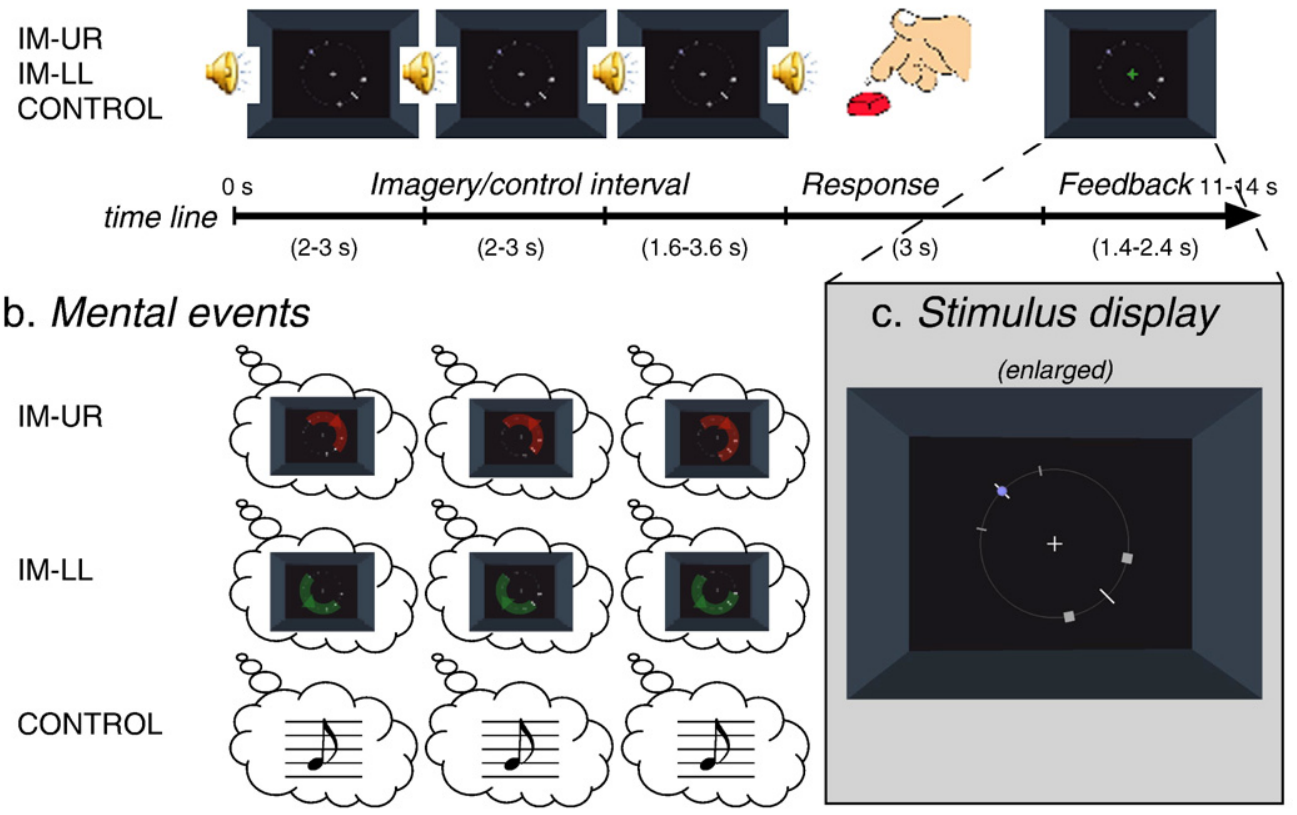

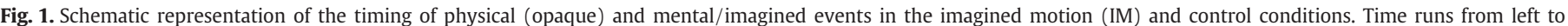

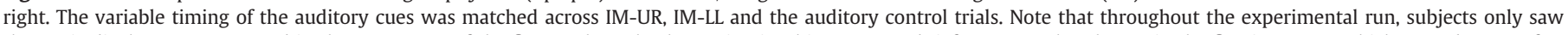

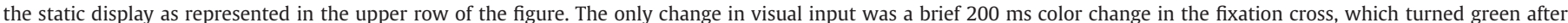

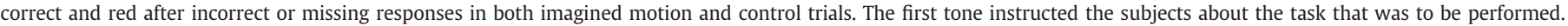

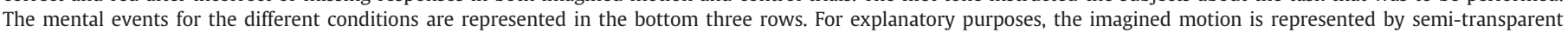
traces (red for IM-UR and green for IM-LL), with arrows indicating the direction for each trial epoch. 
Pure sine wave auditory stimuli were generated in Presentation's Audiospace workspace extension. We created stimuli of stable pitch $(300,500,750$, and $1000 \mathrm{~Hz})$ and with a pitch changing at a rate of one octave per second, either decreasing from $1000 \mathrm{~Hz}$ or increasing from $500 \mathrm{~Hz}$. Duration varied between 200 and $563 \mathrm{~ms}$.

Visual stimulation was delivered by MR-compatible video goggles with two OLED (organic light-emitting diodes) displays (MR Vision 2000, Resonance Technology, Northridge, CA). The displays had a width of $30^{\circ}$ and a height of $22.5^{\circ}$ (resolution $800 \times 600$ pixel) and the luminance of the gray background was $24.0 \mathrm{~cd} / \mathrm{m}^{2}$. Auditory stimulation was conveyed by an MR-compatible head phone (Commander XG, Resonance Technology, Northridge, CA).

\section{Imagery task}

Participants fixated a white center cross throughout the experiment. The visual display remained unchanged during all trials and different conditions were instructed through auditory cues. In imagined motion (IM) trials, subjects envisioned a blue ball moving back and forth in the upper right (IM-UR) or lower left (IM-LL) visual hemifield (Fig. 1). Auditory cues instructed them about the trial type (IM-UR, IM-LL or control) and imagined motion speed. An auditory cue with raising pitch signaled IM-UR trials starting in clockwise direction from the upper left quadrant and a cue with falling pitch signaled IM-LL trials starting in counter clockwise direction, again starting form the upper left quadrant. Two intermediate cues signaled imagined motion direction reversals, and at a final fourth cue subjects made a button press to indicate the position of the imagined ball with respect to two target squares.

The imagined motion could take four different speeds: $90.0^{\circ} / \mathrm{s}$, $77.1^{\circ} / \mathrm{s}, 67.5^{\circ} / \mathrm{s}$ or $60.0^{\circ} / \mathrm{s}$. The length of the first cue $(375 \mathrm{~ms}, 438 \mathrm{~ms}$, $500 \mathrm{~ms}, 563 \mathrm{~ms}$ ) instructed subjects about the required imagined motion speed, as it corresponded to the time needed for the imaginary ball to reach the first marker in the upper left (small gray bar) from the start position at the white bar in the upper left quadrant. Then, participants adjusted their imagined motion speed to two subsequent auditory cues $(300 \mathrm{~Hz}, 200 \mathrm{~ms})$ that signalled arrival at the reversal bars. These corresponded to the white bars in the lower right quadrant (first reversal) and the upper left quadrant (start position and second reversal). Upon hearing a short fourth cue $(750 \mathrm{~Hz}$, $200 \mathrm{~ms}$ ), subjects indicated by button press which of two target squares in the lower right quadrant was closer to the current position of the imagined ball. Subjects used their right index and middle finger for the button press which they were trained to make within $3 \mathrm{~s}$ after the last (fourth) cue. There was a pause of approximately $2 \mathrm{~s}$ before the next trial started, during which feedback was given by a color change in the fixation cross. The cross turned green for $200 \mathrm{~ms}$ after a correct response (the ball was imagined at the instructed speed and direction and therefore in the correct section of the display at the time of the last tone) and red after a wrong response (the ball was not imagined at the instructed speed and direction and therefore did not end up in the correct section of the display at the time of the last tone) or missing response. Based on subjects' reports after the experiment, we are confident that errors of motion direction did not occur in the experiment. Depending on the speed of the imaginary ball and the timing of the fourth cue, the length of the imagery interval was either $6+/-0.375 \mathrm{~s}, 7+/-0.438 \mathrm{~s}, 8+/-0.500 \mathrm{~s}$ or $9+/-0.563 \mathrm{~s}$. Total trial duration was either $11,12,13$ or $14 \mathrm{~s}$. Subjects were explicitly instructed to create a vivid mental image of the moving ball in the imagined motion trials, and to rely on this imagery for their response. Subjects reported that they found the task difficult, but that they did manage to perform the task using mental imagery.

In the control trials, audiovisual stimulation and timing remained the same, the only difference being that the first cue had a stable frequency $(750 \mathrm{~Hz}$ ) and the last (fourth) cue took a value of $500 \mathrm{~Hz}$ or $1000 \mathrm{~Hz}$ (with equal probability). Again, subjects had to press one of two buttons, this time indicating whether the first tone was higher or lower than the last one, ignoring the two intermediate auditory cues. Fixation intervals of the same variable length as the imagery trials were included, during which there was no auditory stimulation, and participants just rested while maintaining their gaze on the center cross. Subjects were explicitly instructed to refrain from visual imagery during the control trials and fixation intervals.

\section{Eyetracking}

During scanning, the location of the right pupil of twelve subjects was tracked under infrared illumination using the MReyetracking system and the Visuastim Digital Glasses (Resonance Technology) inside the magnet and Viewpoint Software (Arrington Research, Scottsdale, AR). The eyetraces were further analyzed using Matlab (The MathWorks, Natick, MA) and SPSS (Rel. 15.0.1. 2006, for Windows; Chicago: SPSS Inc.). Processing included linear trend removal from the horizontal and vertical traces, blink removal and detection of fixation losses. Blinks were defined as those time points during which the pupil could not be recorded (indicating eye-lid closure). Time-points $200 \mathrm{~ms}$ before and after these points were also removed to account for the time to reach full closure of the eye-lid. A fixation loss was defined as an eye position over $3^{\circ}$ of visual angle away from the screen's center for $150 \mathrm{~ms}$ or more. The relative blink time and relative fixation time were calculated for each condition separately, and a repeated measurement ANOVA was performed to check for systematic differences between the imagery and control conditions. One subject was removed from the eyetracking analysis because signal loss occurred more than $50 \%$ of the time, due to positioning problems with the infrared camera. Another subject was removed from all further analyses because the spatial pattern of gaze positions showed that he tracked the imaginary ball. The percentage of time that had to be removed due to blinks was $4 \%$ for both imagery conditions and 9\% for the control condition (paired $t$-test: $t(9)=3.0$, $p<0.05$; Supplementary Fig. 1a). Defining eye positions beyond $3^{\circ}$ from fixation for longer than $150 \mathrm{~ms}$ as a loss of fixation, we found that fixation was lost for $5 \%$ of the remaining time points in the imagery trials and for $7 \%$ of the time points in control trials, indicating that fixation was actually slightly better in the imagery conditions (paired $t$-test: $t(9)=2.6, p<0.05$; Supplementary Fig. $1 \mathrm{~b}$ ). Six out of the ten subjects included in the eyetracking analysis showed some anisotropy in the gaze position distribution (Supplementary Fig. 1c), with slightly more gaze points falling on the upper left to lower right diagonal. The anisotropy was equal across the imagery and control conditions. We therefore think that it is not task-related, but might rather be linked to the specific characteristics of the stimulus display that was equal across conditions and contained most objects in the upper left and lower right corner.

We also performed the analysis at a lower threshold, defining fixation loss as an eye position beyond $1.5^{\circ}$ from fixation for over $150 \mathrm{~ms}$. We found there as no significant difference between conditions at this more strict threshold (IM-UR: $14.4 \%$, IM-LL:12. 3\%, Control: 16.6\%; paired-samples t-tests: IM-UR vs. Control $t(9)=$ $-0.822, p=0.433$; IM-LL vs. Control $t(9)=-1.748, p=0.114$ ). However, the number of detected eye-movements and the number of false positives increased, which might make the detection of differential activity between conditions less conservative.

\section{fMRI data acquisition}

Scanning was performed on a $3 \mathrm{~T}$ Siemens Allegra scanner (Siemens, Erlangen, Germany). For each participant, scanning included the acquisition of six blood oxygenation level-dependent (BOLD) fMRI runs, including four runs of the imagined motion experiment, an hMT/V5+ localizer experiment and a polar angle retinotopic mapping. A gradient-recalled echo-planar imaging sequence was used, with 500 Volumes, 17 slices, $1 \mathrm{~mm}$ gap. 
$3.4 \times 3.4 \times 5.0 \mathrm{~mm}^{3}$ voxels, $1 \mathrm{~s}$ repetition time (TR), $30 \mathrm{~ms}$ echo time (TE), $62^{\circ}$ flip angle (FA) and $220 \mathrm{~mm}^{2}$ field of view (FOV) for the imagined motion experiment. The slices were oriented to reach a total coverage of the occipital and parietal lobes. Start of each trial was synchronized with the acquisition of the fMRI volumes. Each run had at least eight IM-UR, IM-LL, control and fixation trials, which were intermixed in a one-back randomization procedure implemented in Matlab. This ensured a trial order in which each trial type was equally often preceded by any other trial type. An extra fixation period and three additional random trials at the start of the run were not taken into account in the analyses.

For both mapping experiments, functional MR volumes were recorded consisting of 34 slices (in-plane resolution: $3.3 \times 3.3 \mathrm{~mm}^{2}$, FOV: $210 \times 210 \mathrm{~mm}$, slice thickness: $2 \mathrm{~mm}, 0.2 \mathrm{~mm}$ gap, flip angle: $80^{\circ}$ ) yielding a total coverage of the occipital and posterior temporal lobe. Volume TR was $2080 \mathrm{~ms}$ (TE = $30 \mathrm{~ms}$ ).

Each scanning session included the acquisition of a high-resolution magnetization-prepared rapid acquisition gradient echo (MPRAGE) sequence for coregistration and anatomical localization of functional data (160 slices; Echo Time (TE) 4 ms, Repetition Time (TR) 2250 ms, voxel size $1.0 \times 1.0 \times 1.0 \mathrm{~mm}^{3}$; $\left.8^{\circ} \mathrm{FA} ; 256 \times 256 \mathrm{FOV}\right)$.

\section{FMRI data preprocessing}

The BrainVoyager QX software package (Brain Innovation, Maastricht, the Netherlands) was used for fMRI data analysis and visualization. Preprocessing of the functional data as described previously (Weigelt et al., 2007) included (1) 3-D motion correction, (2) linear trend removal and temporal high-pass filtering at $0.01 \mathrm{~Hz}$, and (3) slice scan-time correction with sinc interpolation. The functional and structural 3-D data sets were transformed into Talairach coordinate space (Talairach and Tournoux, 1988). The recorded high-resolution anatomies were used for surface reconstruction, which included gray/white matter segmentation based on intensity values. The cortical surfaces were slightly smoothed and inflated (Kriegeskorte and Goebel, 2001).

\section{Data analysis imagery experiment}

\section{Behavioral data}

Using SPSS, a repeated measures analysis of variance (rmANOVA) was calculated on the reaction times and the accuracy (\% correct), with condition as within-subjects factor (IM-UR, IM-LL and Control).

\section{Whole brain GLM analysis}

In three participants, one run had to be discarded due to excessive head movements. The remaining 45 runs were entered into a random effects (RFX) general linear model (GLM) analysis to test for regionally specific effects. Separate boxcar predictors were defined for each trial type (IM-UR, IM-LL and control) with separate predictors for the error trials. Predictors were convolved with a two-gamma model of the hemodynamic response. A statistical parametric map (SPM) for the contrast between IM-UR and IM-LL versus control predictors was computed to localize brain regions with a significantly stronger response on imagined motion trials. Statistical maps were thresholded at $t(11)=4.44, p=0.001$, and corrected for multiple comparisons at $p<0.05$ using the cluster-size estimation algorithm (Forman et al., 1995). With an estimated spatial auto-correlation of $32.9 \mathrm{~mm}^{3}$ at FWHM (1.218 interpolated $3 \times 3 \times 3 \mathrm{~mm}^{3}$ functional voxels) this resulted in a cluster threshold of $94 \mathrm{~mm}^{3}$.

\section{Localizer experiments and ROI-based data analysis}

We applied standard mapping procedures used and described previously (Muckli et al., 2002; Sereno et al., 1995). Participants were instructed to fixate at a central white fixation cross.
Polar angle retinotopic mapping was used to localize the borders of V1, V2 and V3. A flickering checkerboard wedge (22.5 polar angle) appeared at the right horizontal meridian and rotated clockwise completing 12 full cycles of $360^{\circ}$, each of which lasted for 32 TRs (66.56 s). Polar angle retinotopic maps were computed using a linear cross-correlation analysis. The resulting phase encoded map was projected on corresponding surface patches of the reconstructed cortical sheet. For each subject, the borders of V1, V2 and V3 were manually drawn on the inflated cortical surface reconstruction, and colored in blue, green and yellow, respectively (Fig. $3 \mathrm{~b}$ and Supplementary Fig. 2). In V1, three different eccentricity zones were defined by drawing lines at approximately equal distances along the anterior posterior axis (Fig. 3b and Supplementary Fig. 2). We expect the imagery trace at $5.3^{\circ}$ visual angle to lie in the second eccentricity zone, based on estimates of cortical magnification in V1 (Sereno et al., 1995). Subsequently, ROIs were defined in dorsal and ventral and left and right V1, V2 and V3 and in the six dorsal and six ventral V1 eccentricity zones by expanding the defined surface patches with $-1 \mathrm{~mm}$ and $3 \mathrm{~mm}$ along the vertex normals.

To test whether the BOLD signal changed when imagined motion (IM) passed through a visual field quadrant, we computed the IM in quadrant percent signal change by averaging the IM-LL and IM-UR parameter estimates (beta values) from the quadrants that were expected to be most affected by these conditions (the right dorsal quadrant for IM-LL and left ventral quadrant for IM-UR). An IM in opposite quadrant percent signal change was computed by averaging the IM-LL beta value from the left ventral quadrant and the IM-UR beta value from the right dorsal quadrant. A control percent signal change was computed as the average of the beta values for the control task condition in the left ventral and right dorsal quadrant. The percent signal change for these three retinotopic conditions were computed for V1, V2 and V3 separately, and tested (using SPSS) in a repeated measures design with visual area and retinotopic condition as the within-subjects factors. We expected a main effect of condition, with a greater percent signal change for the IM in quadrant condition than both the IM in opposite quadrant and the Control condition. To explore whether this effect would be different for different eccentricity ranges, the test was repeated within the different eccentricity zones of V1. To get a more detailed impression of the temporal characteristic of the hemodynamic response, the event-related time courses were extracted using a deconvolution design (Dale and Buckner, 1997). The hemodynamic response function for each trial was estimated on the basis of a GLM, with thirty stick predictors (one predictor per volume) covering the temporal extent of the three different retinotopic conditions described above.

Human hMT/V5+ was localized using expanding low contrast random-dot-flowfield patterns covering a visual field of $22.5^{\circ}$ by $30^{\circ}$ visual angle. Static random-dot patterns, flickering random-dot patterns, moving random-dot flowfields and flickering moving random-dot flowfields were presented in alternation, separated by a fixation period. Each block lasted 6 TRs ( $12 \mathrm{~s}$ ). There were 5 blocks for the static conditions (two with and three without flicker), and 5 blocks for the flowfield conditions (two with and three without flicker). A standard general linear model (GLM) was used, in which the BOLD response to each condition was modeled by a boxcar function convolved with a two-gamma hemodynamic response function (HRF). For each individual subject, the flowfield $>$ static contrast map was initially thresholded at $t=1.95, p=0.05$ (uncorrected). Human MT/V5+ was defined as activated gray matter (two or more contiguous functional voxels) at or close to the crossing of the ascending limb of the inferior temporal and lateral occipital sulcus (Watson et al., 1993), and nearest to the average Talairach coordinates $(x=-45, y=-67, z=1 ; x=45, y=-66, z=1)$ reported in a meta-analysis (Slotnick et al., 2005). We wanted to restrict our analyses to the core of hMT/V5+ and created small regions of interest that focus subsequent Granger Causality Mapping 
on pure hMT/V5+ connectivity without including neighboring regions. Therefore, regions of interest were selected by increasing the $t$-value to the highest value (always over $t=1.95, p=0.05$, uncorrected) at which at least $54 \mathrm{~mm}^{3}$ were activated. The balanced contrast Imagery $>$ Control was computed in a RFX multi-subject ROI GLM. To explore the directed influence to and from the mapped hMT/ $\mathrm{V} 5+$ regions during the imagined motion experiment we performed Granger causality mapping (see below).

\section{Granger causality mapping}

The directed influence between hMT/V5+ and other regions of the brain during mental imagery was investigated using Granger causality mapping. This approach explores effective connectivity in fMRI data using the concept of Granger causality (Roebroeck et al., 2005). Granger causality maps (GCMs) are statistical maps of the influence from a designated reference region to all other regions in the brain and from all other brain regions to the reference region. Taking the individually localized left hMT/V5+ ROIs as reference regions, we mapped both outgoing influence to other targets in the brain, and incoming influence from other source regions. Conceptually, source activations represent regions whose activation consistently predicts the future activation (i.e. next time-point) of hMT/V5+. Hence, these source regions are hypothesized to have exerted a task-related causal influence on the cortical activation of hMT/V5+. Target activations represent regions that are consistently predicted by the past (i.e. previous time-point) of hMT/V5+, and thus are hypothesized to be causally influenced by hMT/V5+.

Individual GCMs were computed as detailed in Roebroeck et al. (2005), taking the average time course across the left hMT/V5+ ROI, with separate GCMs reflecting the influences in the two imagined motion conditions and those during control. Only the left hMT/V5+ was used because this could be mapped in all subjects. The maps were subsequently smoothed with a Gaussian kernel of $8 \mathrm{~mm}$ full-width at half maximum (FWHM). RFX GCMs at the group level were then computed by performing second level one-sample $t$-tests using the variance over single-subject GCMs at a given voxel. All RFX GCMs ( $t$-maps) were thresholded at $p<0.05$, and corrected for multiple comparisons at $p<0.05$ using the cluster threshold method described earlier (Forman et al., 1995). With an estimated spatial auto-correlation of $26.6 \mathrm{~mm}^{3}$ at FWHM (1.098 interpolated $3 \times 3 \times 3 \mathrm{~mm}^{3}$ functional voxels), this resulted in a cluster threshold of $871 \mathrm{~mm}^{3}$.

\section{Results}

Behavioral and fMRI data were recorded while subjects performed an imagined motion (IM) task in the upper right (IM-UR) or lower left (IM-LL) visual hemifield, cued by auditory cues. As a control, subjects performed a working memory task on the auditory cues. Whole brain RFX GLM analysis was performed to identify regions that responded stronger to imagined motion than control. The role of hMT/V5+ and V1-V3 was investigated in more detail using a multi-subject analysis on separately localized region-of-interest. Effective connectivity between hMT/V5+ and the rest of the brain was explored using Granger causality mapping.

\section{Behavioral data}

There was no significant difference in reaction times between the control, IM-UR, and IM-LL conditions (rmANOVA, control $=1335 \mathrm{~ms}$, IM-UR $=927 \mathrm{~ms}$, IM-LL $=1183 \mathrm{~ms}, F(2,22)=2.05, p=0.15$; Supplementary Fig. 3a). The response accuracy did differ (rmANOVA, control $=97 \%$, IM-UR $=84 \%, I M-L L=87 \%, F(2,22)=19.41, p<0.05$; Supplementary Fig. 3b), although there was no significant difference between the imagery conditions (difference contrast: $F(1,11)=1.15$, $p=0.307$ ), average accuracy was significantly higher in the control condition than in the IM-UR and IM-LL conditions (difference contrast: $F(1,11)=40.17, p<0.05$; see Supplementary Fig. 3 for details).

\section{fMRI data}

\section{Whole brain GLM analysis}

The cortical network involved in the imagery task (Table 1 and Supplementary Fig. 4) comprised bilateral superior parietal lobule (SPL, BA 7), inferior parietal lobule (IPL, BA 40) and superior frontal gyrus (SFG, BA 6). In the left hemisphere, this contrast revealed a significantly activated cluster in the middle occipital gyrus (MOG). In the right hemisphere, it exposed clusters in medial frontal gyrus (medial FG, BA 6), anterior insula and the basal ganglia (BG). This network was revealed by RFX group analysis using the balanced contrast between motion imagery and control ([IM-UR, IM-LL] $>2$ * Control; $t(11)=4.44, p=0.001$, cluster size corrected at $p<0.05)$.

At a lower $t$-value of $2.2(p=0.05$, cluster-corrected at $p<0.05)$, we found additional activation hotspots in a region of the left MOG $(x=-45, y=-65, z=1)$ as well as the right MOG $(x=45, y=$ $-58, z=0)$, which is somewhat anterior and superior to the average Talairach coordinates $(x=-45, y=-67, z=-5$ and $x=45, y=-66, z=1)$ reported for hMT/V5+ in a meta-analysis (Slotnick et al., 2005).

The two-tailed $t$-test between motion imagery in the upper right and lower left visual field did not reveal any significantly activated regions (at $t(11)=4.44, p=0.001$, cluster-corrected at $p<0.05$ ). At a lower threshold of $t(11)=3, p=0.01$, cluster-corrected at $p<0.05$ (estimated smoothness of $30.4 \mathrm{~mm}^{3}$ at FWHM, i.e. 1.127 interpolated $3 \times 3 \times 3 \mathrm{~mm}^{3}$ functional voxels; minimum cluster size $217 \mathrm{~mm}^{3}$ ) we found two clusters with a significantly stronger response during IM-LL and one cluster with a significantly stronger response during IM-UR in early visual cortex. By projecting a 3D rendering of the polar mapping results on the 3D statistical map, we determined that the location of these clusters corresponded to right dorsal V2/V3, right V1 and left ventral $\mathrm{V} 2 / \mathrm{V} 3$, respectively. The corresponding time courses of the activated clusters showed less deactivation when the imagined motion trace passed through the corresponding visual field quadrant (see Supplementary Fig. 5). Retinotopically specific effects of the

Table 1

Regions activated for the comparison Imagined Motion $(\mathrm{IM})>$ Control, $t(11)=4.44, p=0.05$, cluster size corrected

\begin{tabular}{|c|c|c|c|c|c|c|c|c|c|c|c|}
\hline \multirow[t]{2}{*}{ Area } & \multirow[t]{2}{*}{ BA } & \multicolumn{5}{|c|}{ Left hemisphere } & \multicolumn{5}{|c|}{ Right hemisphere } \\
\hline & & $\bar{x}$ & $y$ & $z$ & Volume $\left(\mathrm{mm}^{3}\right)$ & $\overline{\text { \# voxels }}$ & $\bar{x}$ & $y$ & $z$ & Volume $\left(\mathrm{mm}^{3}\right)$ & $\overline{\# \text { voxels }}$ \\
\hline Superior parietal lobule & 7 & -17 & -60 & 51 & 3426 & 59 & 15 & -61 & 52 & 3059 & 53 \\
\hline Inferior parietal lobule & 40 & -33 & -43 & 48 & 364 & 6 & 39 & -42 & 42 & 1026 & 18 \\
\hline Middle occipital gyrus & & -42 & -77 & 10 & 436 & 8 & & & & & \\
\hline Superior frontal/precentral gyrus & 6 & -26 & -9 & 51 & 337 & 6 & 23 & -4 & 52 & 1113 & 19 \\
\hline Medial frontal gyrus & 6 & & & & & & 5 & 16 & 47 & 155 & 3 \\
\hline Anterior insula & & & & & & & 36 & 17 & 3 & 620 & 11 \\
\hline Basal ganglia & & & & & & & 16 & -5 & 7 & 389 & 7 \\
\hline
\end{tabular}

Talairach coordinates of the center of gravity (COG) for each region. BA = Brodmann area. 


\section{a. Individual hMT/V5+ regions of interest}
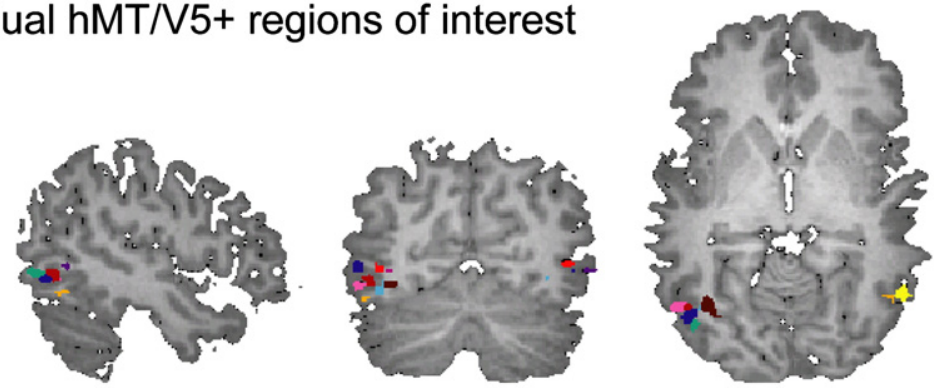

\section{b. Regions influencing Left hMT/V5+ during motion imagery}

1. Left anterior caudate nucleus

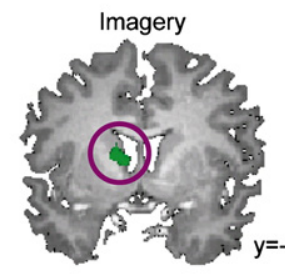

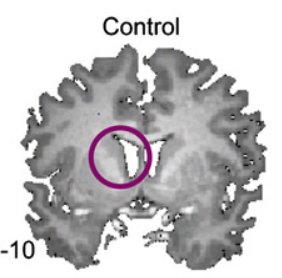

2. Left inferior parietal lobule

$t(11)=2.2$

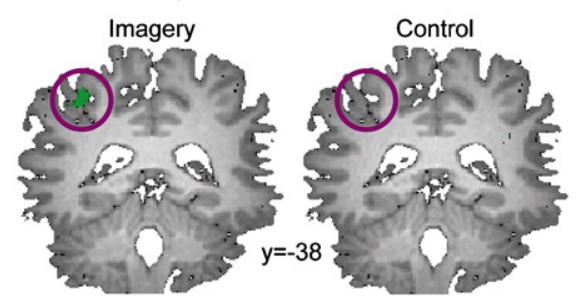

Fig. 2. (a) Individually mapped hMT/V5+ regions projected on the brain of an individual subject. Different colors are used for each subject. (b) RFX Granger causality mapping with the left hMT/V5 + as reference region highlighted the left anterior caudate nucleus (1) and left inferior parietal lobule (2) as source regions sending a significant directed influence to left hMT/V5+ during the imagery conditions but not during control. We did not detect target regions receiving a significant directed influence from left hMT/V5+. The maps were cluster-corrected at $p<0.05$.

imagined motion conditions were further investigated in the ROI analysis of early visual regions (see below).

\section{$h M T / V 5+$ analyses}

hMT/V5 + could be localized in the left hemisphere of all twelve subjects with average Talairach coordinates $x=-44, y=-64$, $z=3$ (Fig. 2a, Table 2 and Supplementary Fig. 6). hMT/V5+ in the right hemisphere was found reliably in seven subjects only $(x=43$, $y=-61, z=5$; Table 2). The balanced contrast between imagery versus control trials was computed for each individual, revealing a significant difference in six out of twelve subjects for left hMT/V5+ and in three out of seven subjects in right hMT/V5+. A multisubject ROI analysis also showed significantly stronger activation during imagery in left hMT/V5+ $(t(11)=2.4, p=0.04)$, but not right hMT/V5+ $(t(6)=1.7, p=0.15)$.

Granger causality mapping revealed significant directed influence to the individually mapped left hMT/V5+ reference from the left anterior inferior parietal lobe (IPL), left anterior caudate nucleus, left thalamus and left middle occipital gyrus during Imagined Motion $(t(11)=2.2, p=0.05$, cluster-corrected $)$. There was no directed influence from left anterior IPL (Talairach coordinates: $x=-34, y=-38$, $z=45)$ and left anterior caudate nucleus $(x=-10, y=0, z=11)$ in the auditory control condition (at $t(11)=1.8, p=0.1$; Fig. $2 \mathrm{~b}$ ).

\section{V1-3 analysis}

Of the twelve subjects included in the fMRI analyses, ROIs within left V1 could be mapped in eleven, and in right V1 in nine subjects. V2 and V3 could be delineated in the left hemisphere of ten subjects, and in the right hemisphere in nine subjects dorsally, and in eight ventrally. In the remaining hemispheres, the visual borders could not be delineated reliably, due to poor signal quality.

We found a significant effect of condition (IM in quadrant, IM in opposite quadrant and control) on the average percent signal change in V1, V2 and V3 (Fig. 3c), in a repeated measures ANOVA (area by condition) for the seven subjects in which all quadrants could be mapped in all areas $(F(2,12)=8.986, p=0.004)$. The effect of condition was due to a significant difference between the imagined motion conditions and control (mean IM in quadrant=

Table 2

Individual hMT $+t$-value and location, $t$-value for balanced contrast Imagined Motion (IM) $>$ Control.

\begin{tabular}{|c|c|c|c|c|c|c|c|c|c|c|c|c|c|c|}
\hline \multirow[t]{2}{*}{ Subject } & \multicolumn{7}{|c|}{ Left hMT+ } & \multicolumn{7}{|c|}{ Right hMT+ } \\
\hline & $\bar{x}$ & $y$ & $z$ & $\begin{array}{l}\text { Volume } \\
\left(\mathrm{mm}^{3}\right)\end{array}$ & \# voxels & $\begin{array}{l}\text { Localizer } \\
t\end{array}$ & $\begin{array}{l}\text { IM }>\text { control } \\
t\end{array}$ & $\bar{x}$ & $y$ & $z$ & $\begin{array}{l}\text { Volume } \\
\left(\mathrm{mm}^{3}\right)\end{array}$ & \# voxels & $\begin{array}{l}\text { Localizer } \\
t\end{array}$ & $\begin{array}{l}\text { IM }>\text { control } \\
t\end{array}$ \\
\hline$\overline{1}$ & -40 & -63 & -1 & 82 & 3 & $1.95^{*}$ & 0.021 & 32 & -66 & 5 & 92 & 4 & $1.95^{*}$ & -1.5 \\
\hline 2 & -46 & -60 & -5 & 66 & 3 & $3.45^{* *}$ & 0.688 & 41 & -59 & -3 & 123 & 5 & $2.95^{* *}$ & $3.035^{* *}$ \\
\hline 3 & -50 & -64 & 9 & 100 & 4 & $3.45^{* *}$ & $4.582^{* *}$ & & & & & & & \\
\hline 4 & -40 & -65 & 8 & 99 & 4 & $1.95^{*}$ & $2.27^{*}$ & 43 & -64 & 10 & 74 & 3 & $2.95^{* *}$ & -0.669 \\
\hline 5 & -47 & -65 & 4 & 138 & 6 & $3.45^{* *}$ & -0.857 & & & & & & & \\
\hline 6 & -52 & -56 & 6 & 150 & 6 & $1.95^{*}$ & $4.159^{* *}$ & 50 & -58 & 3 & 103 & 4 & $2.45^{*}$ & 1.761 \\
\hline 7 & -39 & -68 & 7 & 67 & 3 & $3.45^{* *}$ & $5.767^{* *}$ & 40 & -59 & 5 & 57 & 2 & $3.45^{* *}$ & $2.048^{*}$ \\
\hline 8 & -49 & -63 & 0 & 80 & 3 & $1.95^{*}$ & $4.344^{* *}$ & & & & & & & \\
\hline 9 & -44 & -67 & 1 & 67 & 3 & $4.95^{* *}$ & $-1.992^{*}$ & 45 & -60 & 9 & 85 & 4 & $4.45^{* *}$ & -1.075 \\
\hline 10 & -46 & -59 & 6 & 92 & 4 & $3.12^{* *}$ & 0.24 & 51 & -61 & 7 & 84 & 4 & $2.12^{*}$ & $2.089^{*}$ \\
\hline 11 & -43 & -73 & 3 & 152 & 6 & $1.95^{*}$ & $7.984^{* *}$ & & & & & & & \\
\hline 12 & -35 & -62 & 1 & 123 & 5 & $1.95^{*}$ & -0.412 & & & & & & & \\
\hline
\end{tabular}

Talairach coordinates of the center of gravity (COG) for each region.

$* *: p<0.005$.

$*: p<0.05$ 

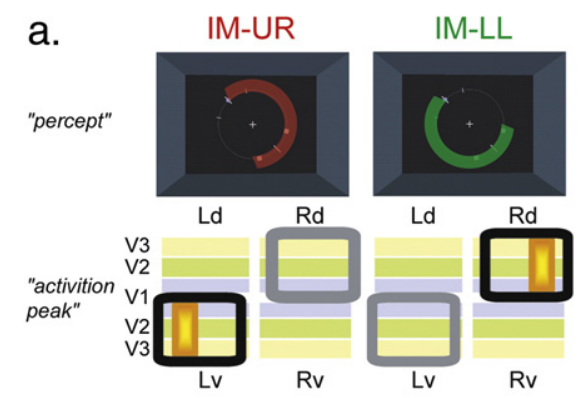

b.
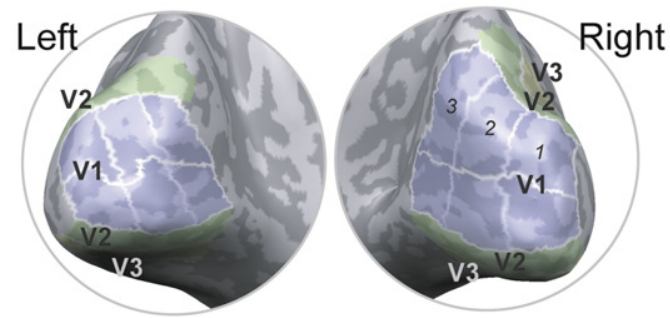

C.
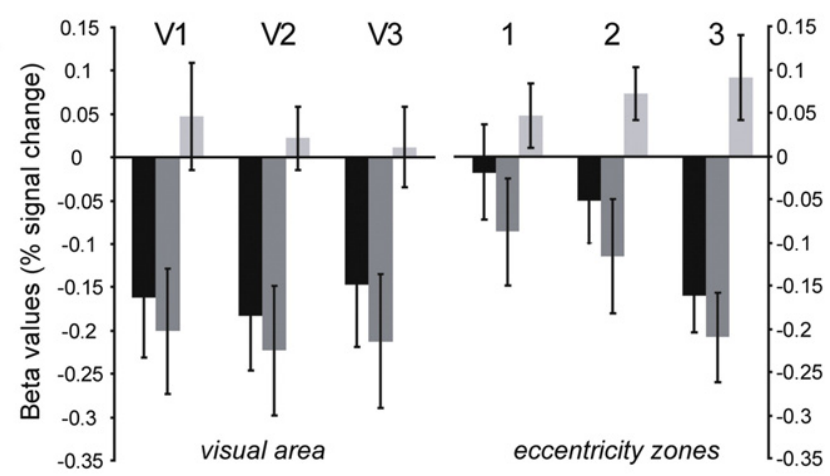
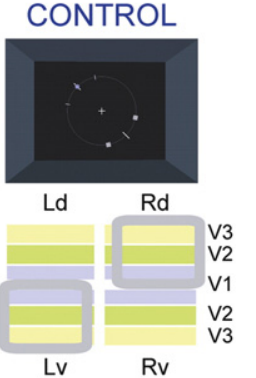

Right

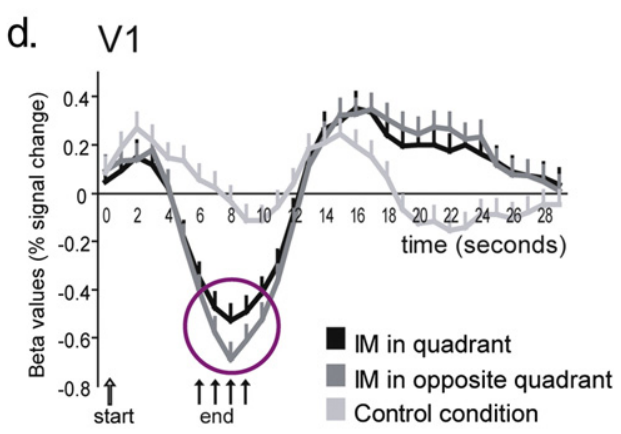

V2

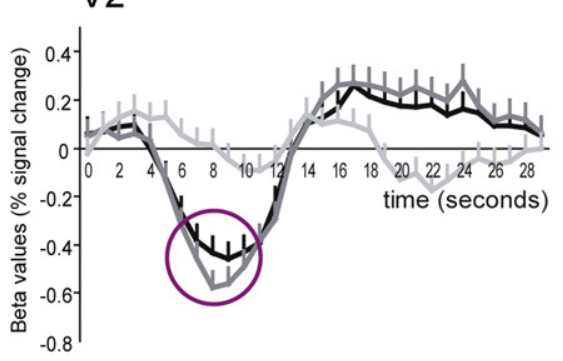

V3

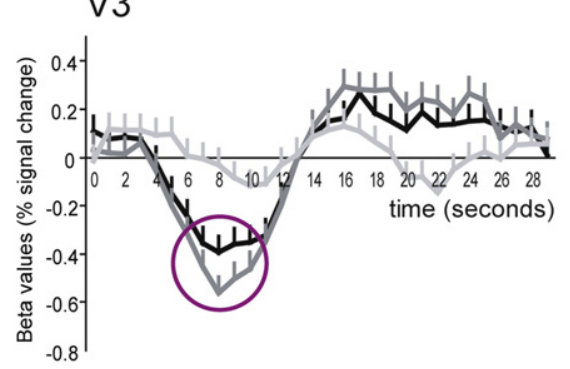

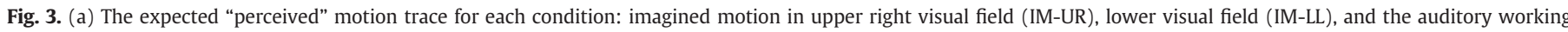

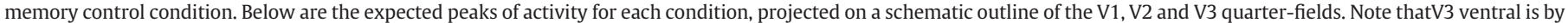

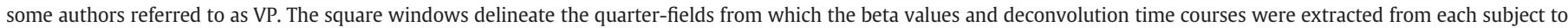

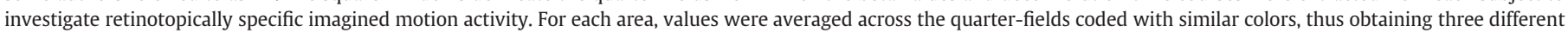

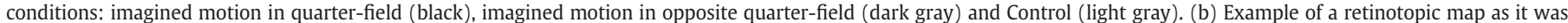

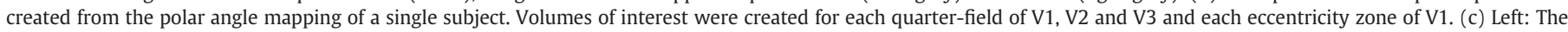

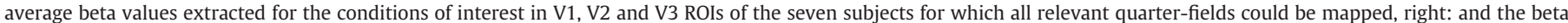

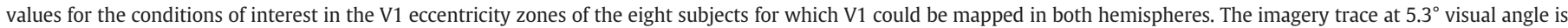

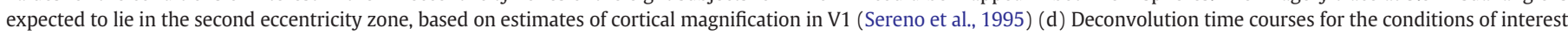

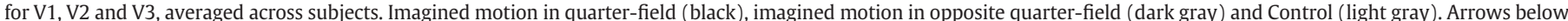

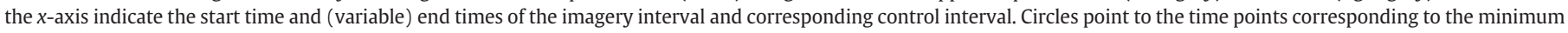
where the difference between "imagined motion in quarter-field" and "imagined motion in opposite quarter-field" reached significance.

-0.093; mean IM in opposite quadrant $=-0.143$; mean control $=$ -0.102 ; planned simple contrasts, IM in quadrant versus control: $F(1,6)=11.870, p=0.014 ; I M$ in quadrant versus $I M$ in opposite quadrant: $F(1,6)=2.354, p=0.176)$. The analysis in the eccentricity zones of the V1 quadrants revealed a main effect of condition $(F(2,14)=15.301, p=0.000)$, a trend for a main effect of eccentricity zone $(F(2,14)=3.387, p=0.063)$, and an interaction between condition an eccentricity $(F(4,28)=8.947, p=0.000)$. The interaction was caused by a difference in the linear change with eccentricity between the IM in quadrant versus control condition $(F(1,7)=57.303$, $p=0.000$ (Fig. 3c).

The deconvolution time courses also showed a specific negative activation with a BOLD-like shape for both imagined motion conditions (Fig. 3d). The average peak latency was $8 \mathrm{~s}$. In correspondence with the pattern observed for the percent signal change over whole trials, the BOLD response was less negative when the imagery trace traversed the visual quarter-field, than when it traversed the opposite visual quarter-field (Fig. 3c). Paired-samples $t$-tests on the peaks of the deconvolution time courses ( $8 \mathrm{~s}$ after stimulus onset) of each individual subject revealed that this difference was significant for $\mathrm{V} 1$ $(t(11)=2.75, p=0.019)$ and showed a trend towards significance for $\mathrm{V} 2(t(10)=2.142, p=0.058)$ and V3 $(t(10)=2.189, p=0.053)$.

\section{Discussion}

Imagery of a moving object evoked strong activity in parietofrontal regions, right anterior insula, right basal ganglia, and left middle occipital gyrus (MOG), as well as mapped hMT/V5+ in the left hemisphere. Left anterior caudate nucleus and left anterior IPL influenced left hMT/V5+ during imagery but not during control. Interestingly, $\mathrm{V} 1, \mathrm{~V} 2$ and $\mathrm{V} 3$ showed a strong negative BOLD response (NBR) during motion imagery, which was attenuated (less negative) when the motion trace traversed the quarter-field.

Apart from hMT/V5+, which we identified in a separate mapping procedure and has been found to show motion-specific activation during perception (Tootell et al., 1995; Zeki et al., 1991) and imagery (Goebel et al., 1998), we do not claim that the other areas reported in this study are necessarily feature-specific as well. There is probably no unique network for mental imagery; it rather shares common brain areas with other major cognitive functions, depending on the nature 
of the imagery task (Barsalou, 2008; Mellet et al., 1998; Moulton and Kosslyn, 2009).

Parietofrontal network activation has also been observed during other spatial imagery tasks (Cohen et al., 1996; Formisano et al., 2002; Mellet et al., 1996; Podzebenko et al., 2005). We found the strongest activation in the left superior parietal lobule (SPL), which might be crucial in the generation of mental images (Sack et al., 2005). There was also strong activation in the right SPL, which has been argued to support spatial comparison (Sack et al., 2005). In the current study, subjects had to continuously update their mental image, compare its trajectory to the display, and its speed to the location of the squares and timing of the auditory cues. The SPL is also important in attentional tracking (Culham et al., 1998; Jovicich et al., 2001) and occluded motion (Assad and Maunsell, 1995; Shuwairi et al., 2007).

The lower accuracy during imagery indicates that imagery was more difficult to perform than the control task. This might have increased the imagery-related differences in parietofrontal areas (Corbetta and Shulman, 2002). However, early visual regions and hMT/V5 + were the main focus of this study, and we therefore considered it more important to control for low-level sensory characteristics (auditory cues and visual displays) than for higherorder task demands.

Motion imagery significantly activated the left middle occipital gyrus (MOG). At a lower threshold, the activation was bilateral, partly covering the mapped hMT/V5+ regions. These extrastriate imageryspecific activations suggest that the task was indeed solved using a visual strategy, involving motion perception.

Comparing its location to the available retinotopic maps, the MOG region most likely corresponds to area V3b, containing a full map of the contralateral hemifield (Swisher et al., 2007; Wandell et al., 2005). $\mathrm{V} 3 \mathrm{a} / \mathrm{b}$ was found to show increased responses to kinetic boundaries (Larsson and Heeger, 2006), although responses to other types of object boundaries might be equally strong (Zeki et al., 2003).

\section{Human MT/V5 + in motion imagery}

We found significant imagery-related activation in hMT/V5+ in the left, but not in the right hemisphere. This might be due to a lack of power, because right hMT/V5+ could only be mapped in seven subjects (as opposed to twelve for left hMT/V5+). Three out of these seven subjects showed significantly stronger activity during imagery than control. There was also slightly less activity in the right occipitotemporal cortex at more lenient thresholds in the whole brain RFX map. Previous studies did not report lateralization effects in hMT/V5+ during motion imagery (Goebel et al., 1998; Slotnick et al., 2005), although stronger left hemispheric activation was reported for face imagery (Ishai et al., 2002), and image generation (Farah, 1989; Sack et al., 2005).

We did not find significant activation in hMT/V5+ when contrasting imagined motion in the upper right (IM-UR) versus imagined motion in the lower left quadrant (IM-LL). The imagined motion crossed the midline in both conditions, but the proportion of time and space in the right hemifield was larger for IM-UR and vice versa in the left hemifield for IM-LL. This could cause a net activation difference in regions with a retinotopic organization. However, the likelihood of finding retinotopic effects in hMT/V5+ for ipsi- versus contralateral motion would have been low in the present study, given the relatively large voxel size and the fact that only a posterior subregion of hMT/V5+ shows hemispheric specificity, especially within $4^{\circ}$ of fixation (Huk et al., 2002). On the other hand, for the early visual regions, which cover a large portion of the cortex and show strong retinotopic specificity, finding retinotopic effects should in principle have been possible with the current set-up. Indeed, we do find some retinotopic effects in these regions both in the whole brain and ROI-based analyses. The relative weakness of these effects could be due to a lack of retinotopic specificity in the feedback connections from hMT/V5+.

Areas of the visual processing stream have generally been reported to show lower activation during imagery than perception (Goebel et al., 1998; Ishai et al., 2000, 2002; Mellet et al., 1998). To our knowledge, only one study (Slotnick et al., 2005) reported higher hMT/V5+ activation during imagery than perception, but this might have been due to attentive tracking of the moving arcs in the display during imagery (Beauchamp et al., 1997; Culham et al., 1998).

In general, the built-up of mental imagery is a slow process (Amedi et al., 2005; Sack et al., 2008). This built-up process and adjustment to the right speed might have been even more strenuous in the current study, because image generation could not rely on a memory trace as in most previous imagery studies, in contrast, the mental image had to be generated based on general sensory experience. Images generated from long-term memory were found to produce less activation in visual cortex than specific exemplar images from short-term memory (Ishai et al., 2000, 2002). This might explain why hMT/V5+ activity was less strong in the current study where imagery was based on rules and general experience, whereas parietal and more general visual areas showed stronger activity.

\section{GCM - Granger causality mapping}

We found imagery-specific directed influences from left IPL and left anterior caudate nucleus to left hMT/V5+. The connection from left anterior caudate nucleus to hMT/V5+ might be indirect and passing through the thalamus, since the head of the caudate predominantly receives cortical projections from prefrontal and posterior parietal cortex (Utter and Basso, 2008). The left IPL area in the current study might form part of the intraparietal sulcus, more particularly corresponding to human ventral intraparietal area (VIP). This region has a direct anatomical connection to hMT/V5+ in nonhuman primates (Maunsell and van Essen, 1983). Macaque VIP encodes modality invariant motion in near-extrapersonal space (Schlack et al., 2003, 2005). During imagined motion, left IPL, slightly more anterior than the IPL activation found in the RFX GLM analysis, might send the outcome of the image generation process in parietal cortex to left hMT/V5+. The latter may use this information to compute speed and construct the perceptual experience of motion.

Previous studies using various methods support the importance of causal connections between posterior parietal cortex and MT when attending to motion. Feedback from posterior parietal neurons (area LIP) was found to account for attention-enhanced MT responses in macaques (Saalmann et al., 2007). A causal connection between right IPS locus and hMT/V5 + was demonstrated during motion perception, using concurrent transcranial magnetic stimulation (TMS) and fMRI (Ruff et al., 2008), whereas there are indications that additional influence from frontal eye-fields (FEF) is not needed to account for hMT/V5+ modulations (Friston and Buchel, 2000; Ruff et al., 2008). Our finding suggests that parietal influences also induce hMT/V5+ modulations during imagined motion.

However, the current finding does not exclude that additional causal connections exist with e.g. prefrontal cortex and early visual areas. fMRI-based difference GCMs have lower sensitivity for reciprocal interactions. Also, the temporal sampling rate of $1 \mathrm{~s}$ is high for fMRI, but relatively low for neuronal processing. Interactions at this time scale are likely to reflect modulatory processes related to attention and cognitive control (Roebroeck et al., 2005), but faster processes might go undetected.

\section{The role of V1, V2 and V3 in motion imagery}

We observed a negative BOLD response (NBR) in regions of retinotopic visual cortex during imagined motion. This might reflect inhibition to prevent potential visual input from interfering with 
ongoing imagery processing in higher visual areas such as hMT/V5+. NBR in early sensory regions has been linked to reduced neuronal activity (Shmuel et al., 2002, 2006) and neuromodulator-mediated vasoconstriction (Devor et al., 2008). Functionally, the NBR has been associated with increased perceptual thresholds (Kastrup et al., 2008). As most task-relevant sensory information was contained in the auditory cues, the NBR in lower-order visual areas could reflect crossmodal inhibition (Buckner et al., 1996) modality-specific imagery (Amedi et al., 2005) and memory retrieval (Azulay et al., 2009). This might imply that the retinotopically specific imagery task could be solved using higher-order motion-specific visual areas only.

However, the NBR in early visual regions did show some retinotopic specificity. It was stronger if the imagined motion crossed the respective part of (imagined) visual space (contralateral to the quarter-field in visual cortex) than when it crossed the opposing part of (imagined) visual space (ipsilateral to the cortical quarter-field) (Fig. 3). This could reflect a net attenuation when the bulk of voxels corresponding to off-trace processing are downregulated below baseline, whereas regions corresponding to the motion trace were selectively enhanced, potentially even showing a positive BOLD. Nevertheless, our data showed no indication of an interaction between eccentricity and imagery condition (Fig. 3c). Instead, there appears to be a global down-regulation with a central to peripheral gradient, independent whether the imagery passed through the quarter-field. The quarter-field-specific attenuation of the NBR during imagined motion might be caused by a global baseline increase related to increased attention to the respective part of visual space (Kastner et al., 1999; McMains et al., 2007). A similar NBR attenuation was also reported in an attentional cueing task for catch trials where the expected visual display was not presented (Munneke et al., 2008). Early visual areas showed a global NBR when the expected search display was not presented, but the NBR was somewhat less negative in the cued as compared to the uncued hemifield. A recent study (Heinemann et al., 2009) found that directing attention to a foveal task caused a small NBR increase in the peripheral visual cortex (significant in the right hemisphere only), but no interaction between eccentricity and the (presence of absence of the) task was observed. The strongest increase of the peripheral deactivation was related to bottom-up effects induced by adding peripheral distracters. Thus, just as the present study, these two studies found that the NBR induced by top-down effects showed no or only slight retinotopic specificity.

Quite a number of imagery studies reported activation in the occipitotemporal and parieto-occipital cortex rather than striate visual cortex (Formisano et al., 2002; Ishai et al., 2000; Knauff et al., 2000; Mellet et al., 1998; Roland and Gulyas, 1995; Wheeler et al., 2000). Previous studies involving short-term memory based motion imagery found slight activation in V3 and V2 (Goebel et al., 1998) and V1 (Slotnick et al., 2005). Feedback from hMT/V5+ was shown to induce $\mathrm{V} 1$ activity to an illusory motion trace when a motion percept was induced by alternating flashes (Muckli et al., 2005; Sterzer et al., 2006). These results show that imagined or (illusory) motion can in principle induce positive BOLD in early visual cortex. We therefore believe that the content of the visual imagery is not the key explanation for the negative BOLD effects observed here - rather, we think that this finding of negative rather than positive activation relates to the fact that the stimuli could not be recovered from specific short-term or long-term memories. Instead, imagined motion had to be constructed based on rules and general sensory experience stored in long-term memory. Without a memory trace or driving bottom-up visual input, it might be impossible for top-down influences to induce activity in early sensory cortices.

On top of the general deactivation in early visual areas, we observed a much smaller retinotopically specific modulation related to the location of spatial imagery, as evidenced by the slightly less negative BOLD in the imagined quadrants and more negative BOLD in the non-imagined quadrants. Our two imagery conditions served as an intrinsic control for the location of the imagery and covert spatial attention. With matched task requirements, difficulty and general level of attention, directing motion imagery to one quadrant - and away from the other quadrant - is the most optimal way to investigate spatially specific effects as observed for example in spatial attention (e.g. Kastner et al., 1999). However, the main effect is in both cases a decrease of BOLD signal relative to the non-imagery conditions in which the sensory stimulus is identical but the instruction is to do an auditory task. Performing an auditory control task has so far been seen as a good baseline to observe positive BOLD signal during visual imagery.

The modest retinotopic effects could be specific to spatial mental imagery but could also be due to the covert spatial attention associated with the imagery. In their paper on early retinotopic activity in visual imagery, Slotnick et al. (2005) found a greater fraction of perception-related voxels active in the imagery versus the attention conditions, suggesting that there might be a contribution of imagery-related processes to the activation in early retinotopic cortex separate from (spatial) attention. Importantly, however, there was no difference in phase-phase correspondence between perception and imagery and perception and (spatial focused) attention, that is, the additional effects of imagery on top of attention appeared not to be strongly retinotopically specific. Separating the contributions of imagery and (spatial) attention to the already small retinotopically specific effects we observed for rule-based motion imagery will be a challenging task requiring much future investigation. However, the potential results of these investigations are not expected to change the interpretation of our main finding of global deactivation of early visual regions, which was independent of the location of the imagery.

The primary goal of this study was to eliminate the effects of (short- or long-term) memory in the investigation of the effects of mental imagery on separately localized category-specific (hMT/V5+) and early visual regions. The current study indicates that rule-based construction of visual (motion) imagery might not depend on activation in early visual cortex, but rather be related to activation of extrastriate areas (lateral occipital cortex, potentially V3b, and hMT/V5+) through top-down influences originating in the inferior parietal lobule. Whether the observed effects are specific to motion imagery or also occur in other tasks involving similar spatial attentional demands and different types of imagery is a matter for future studies.

\section{Acknowledgments}

This work was supported by a grant from the bilateral cooperation programme of the German Research Foundation [grant number MU 2358/1-2 to L.M.] and the Netherlands Organization for Scientific Research [grant number DN 55-19]. We would like to thank all participants, Arjen Alink, and the members of the core structure of the Brain Imaging Center in Frankfurt am Main, Germany. We would like to thank Elia Formisano and David Linden for fruitful discussions.

\section{Appendix A. Supplementary data}

Supplementary data associated with this article can be found, in the online version, at doi:10.1016/j.neuroimage.2009.07.055.

\section{References}

Amedi, A., Malach, R., Pascual-Leone, A., 2005. Negative BOLD differentiates visual imagery and perception. Neuron 48, 859-872.

Assad, J.A., Maunsell, J.H., 1995. Neuronal correlates of inferred motion in primate posterior parietal cortex. Nature 373, 518-521.

Azulay, H., Striem, E., Amedi, A., 2009. Negative BOLD in sensory cortices during verbal memory: a component in generating internal representations? Brain Topogr. 21, 221-231.

Barsalou, L.W., 2008. Grounded cognition. Annu. Rev. Psychol. 59, 617-645. 
Beauchamp, M.S., Cox, R.W., DeYoe, E.A., 1997. Graded effects of spatial and featura attention on human area MT and associated motion processing areas. J. Neurophysiol. 78, 516-520.

Bisley, J.W., Zaksas, D., Droll, J.A., Pasternak, T., 2004. Activity of neurons in cortical area MT during a memory for motion task. J. Neurophysiol. 91, 286-300.

Buckner, R.L., Raichle, M.E., Miezin, F.M., Petersen, S.E., 1996. Functional anatomic studies of memory retrieval for auditory words and visual pictures. J. Neurosci. 16, 6219-6235.

Cohen, M.S., Kosslyn, S.M., Breiter, H.C., DiGirolamo, G.J., Thompson, W.L., Anderson, A.K., Brookheimer, S.Y., Rosen, B.R., Belliveau, J.W., 1996. Changes in cortical activity during mental rotation. A mapping study using functional MRI. Brain 119 (Pt. 1), 89-100.

Corbetta, M., Shulman, G.L., 2002. Control of goal-directed and stimulus-driven attention in the brain. Nat. Rev. Neurosci. 3, 201-215.

Culham, J.C., Brandt, S.A., Cavanagh, P., Kanwisher, N.G., Dale, A.M., Tootell, R.B., 1998 Cortical fMRI activation produced by attentive tracking of moving targets. J. Neurophysiol. 80, 2657-2670.

Dale, A., Buckner, RL, 1997. Selective averaging of rapidly presented individual trials using fMRI. Hum. Brain Mapp. 5, 329-340.

Devor, A., Hillman, E.M., Tian, P., Waeber, C., Teng, I.C., Ruvinskaya, L., Shalinsky, M.H., Zhu, H., Haslinger, R.H., Narayanan, S.N., Ulbert, I., Dunn, A.K., Lo, E.H., Rosen, B.R. Dale, A.M., Kleinfeld, D., Boas, D.A., 2008. Stimulus-induced changes in blood flow and 2-deoxyglucose uptake dissociate in ipsilateral somatosensory cortex. J. Neurosci. 28, 14347-14357

Farah, M.J., 1989. The neural basis of mental imagery. Trends Neurosci. 12, 395-399.

Forman, S.D., Cohen, J.D., Fitzgerald, M., Eddy, W.F., Mintun, M.A., Noll, D.C., 1995 Improved assessment of significant activation in functional magnetic resonance imaging (fMRI): use of a cluster-size threshold. Magn. Reson. Med. 33, $636-647$.

Formisano, E., Linden, D.E., Di Salle, F., Trojano, L., Esposito, F., Sack, A.T., Grossi, D., Zanella, F.E., Goebel, R., 2002. Tracking the mind's image in the brain I: timeresolved fMRI during visuospatial mental imagery. Neuron 35, 185-194.

Friston, K.J., Buchel, C., 2000. Attentional modulation of effective connectivity from V2 to V5/MT in humans. Proc. Natl. Acad. Sci. U. S. A. 97, 7591-7596

Goebel, R., Khorram-Sefat, D., Muckli, L., Hacker, H., Singer, W., 1998. The constructive nature of vision: direct evidence from functional magnetic resonance imaging studies of apparent motion and motion imagery. Eur. J Neurosci. 10, 1563-1573

Harrison, S.A., Tong, F., 2009. Decoding reveals the contents of visual working memory in early visual areas. Nature 458, 632-635.

Heinemann, L., Kleinschmidt, A., Muller, N.G., 2009. Exploring BOLD changes during spatial attention in non-stimulated visual cortex. PLoS One 4, e5560.

Huk, A.C., Dougherty, R.F., Heeger, D.J., 2002. Retinotopy and functional subdivision of human areas MT and MST. J. Neurosci. 22, 7195-7205.

Ishai, A., Ungerleider, L.G., Haxby, J.V., 2000. Distributed neural systems for the generation of visual images. Neuron 28, 979-990.

Ishai, A., Haxby, J.V., Ungerleider, L.G., 2002. Visual imagery of famous faces: effects of memory and attention revealed by fMRI. NeuroImage 17, 1729-1741.

Jovicich, J., Peters, R.J., Koch, C., Braun, J., Chang, L., Ernst, T., 2001. Brain areas specific for attentional load in a motion-tracking task. J. Cogn. Neurosci. 13, $1048-1058$

Kastner, S., Pinsk, M.A., De Weerd, P., Desimone, R., Ungerleider, L.G., 1999. Increased activity in human visual cortex during directed attention in the absence of visual stimulation. Neuron 22, 751-761.

Kastrup, A., Baudewig, J., Schnaudigel, S., Huonker, R., Becker, L., Sohns, J.M. Dechent, P., Klingner, C., Witte, O.W., 2008. Behavioral correlates of negative BOLD signal changes in the primary somatosensory cortex. Neurolmage 41, 1364-1371.

Knauff, M., Kassubek, J., Mulack, T., Greenlee, M.W., 2000. Cortical activation evoked by visual mental imagery as measured by fMRI. NeuroReport 11, 3957-3962.

Kosslyn, S.M., Thompson, W.L., 2003. When is early visual cortex activated during visua mental imagery? Psychol. Bull. 129, 723-746.

Kriegeskorte, N., Goebel, R., 2001. An efficient algorithm for topologically correct segmentation of the cortical sheet in anatomical MR volumes. Neurolmage 14 329-346.

Larsson, J., Heeger, D.J., 2006. Two retinotopic visual areas in human lateral occipital cortex. J. Neurosci. 26, 13128-13142.

Maunsell, J.H., van Essen, D.C., 1983. The connections of the middle temporal visual area (MT) and their relationship to a cortical hierarchy in the macaque monkey. J. Neurosci. 3, 2563-2586.

McMains, S.A., Fehd, H.M., Emmanouil, T.A., Kastner, S., 2007. Mechanisms of featureand space-based attention: response modulation and baseline increases. J. Neurophysiol. 98, 2110-2121.

Mechelli, A., Price, C.J., Friston, K.J., Ishai, A., 2004. Where bottom-up meets top-down: neuronal interactions during perception and imagery. Cereb. Cortex 14 $1256-1265$

Mellet, E., Tzourio, N., Crivello, F., Joliot, M., Denis, M., Mazoyer, B., 1996. Functional anatomy of spatial mental imagery generated from verbal instructions. J. Neurosci. $16,6504-6512$.

Mellet, E., Petit, L., Mazoyer, B., Denis, M., Tzourio, N., 1998. Reopening the menta imagery debate: lessons from functional anatomy. Neurolmage 8, 129-139.

Moulton, S.T., Kosslyn, S.M., 2009. Imagining predictions: mental imagery as mental emulation. Philos. Trans. R. Soc. Lond. B Biol. Sci. 364, 1273-1280.

Muckli, L., Kriegeskorte, N., Lanfermann, H., Zanella, F.E., Singer, W., Goebel, R., 2002. Apparent motion: event-related functional magnetic resonance imaging of perceptual switches and States. J. Neurosci. 22, RC219.
Muckli, L., Kohler, A., Kriegeskorte, N., Singer, W., 2005. Primary visual cortex activity along the apparent-motion trace reflects illusory perception. PLoS Biol. 3, e265.

Munneke, J., Heslenfeld, D.J., Theeuwes, J., 2008. Directing attention to a location in space results in retinotopic activation in primary visual cortex. Brain Res. 1222, 184-191.

O'Craven, K.M., Kanwisher, N., 2000. Mental imagery of faces and places activates corresponding stiimulus-specific brain regions. J. Cogn. Neurosci. 12, 1013-1023.

Pasternak, T., Greenlee, M.W., 2005. Working memory in primate sensory systems. Nat. Rev. Neurosci. 6, 97-107.

Podzebenko, K., Egan, G.F., Watson, J.D., 2005. Real and imaginary rotary motion processing: functional parcellation of the human parietal lobe revealed by fMRI. J. Cogn. Neurosci. 17, 24-36.

Ranganath, C., DeGutis, J., D'Esposito, M., 2004. Category-specific modulation of inferior temporal activity during working memory encoding and maintenance. Brain Res. Cogn. Brain Res. 20, 37-45.

Roebroeck, A., Formisano, E., Goebel, R., 2005. Mapping directed influence over the brain using Granger causality and fMRI. Neuroimage 25, 230-242.

Roland, P.E., Gulyas, B., 1995. Visual memory, visual imagery, and visual recognition of large field patterns by the human brain: functional anatomy by positron emission tomography. Cereb. Cortex 5, 79-93.

Ruff, C.C., Bestmann, S., Blankenburg, F., Bjoertomt, O., Josephs, O., Weiskopf, N., Deichmann, R., Driver, J., 2008. Distinct causal influences of parietal versus frontal areas on human visual cortex: evidence from concurrent TMS-fMRI. Cereb. Cortex $18,817-827$.

Saalmann, Y.B., Pigarev, I.N., Vidyasagar, T.R., 2007. Neural mechanisms of visual attention: how top-down feedback highlights relevant locations. Science 316, 1612-1615.

Sack, A.T., Camprodon, J.A., Pascual-Leone, A., Goebel, R., 2005. The dynamics of interhemispheric compensatory processes in mental imagery. Science 308, 702-704.

Sack, A.T., Jacobs, C., De Martino, F., Staeren, N., Goebel, R., Formisano, E., 2008. Dynamic premotor-to-parietal interactions during spatial imagery. J. Neurosci. 28, 8417-8429.

Sala, J.B., Rama, P., Courtney, S.M., 2003. Functional topography of a distributed neural system for spatial and nonspatial information maintenance in working memory. Neuropsychologia 41, 341-356.

Schicke, T., Muckli, L., Beer, A.L., Wibral, M., Singer, W., Goebel, R., Rosler, F., Roder, B., 2006. Tight covariation of BOLD signal changes and slow ERPs in the parietal cortex in a parametric spatial imagery task with haptic acquisition. Eur. J. Neurosci. 23, 1910-1918.

Schlack, A., Hoffmann, K.P., Bremmer, F., 2003. Selectivity of macaque ventral intraparietal area (area VIP) for smooth pursuit eye movements. J. Physiol. 551, 551-561.

Schlack, A., Sterbing-D'Angelo, S.J., Hartung, K., Hoffmann, K.P., Bremmer, F., 2005. Multisensory space representations in the macaque ventral intraparietal area. J. Neurosci. 25, 4616-4625.

Sereno, M.I., Dale, A.M., Reppas, J.B., Kwong, K.K., Belliveau, J.W., Brady, T.J., Rosen, B.R., Tootell, R.B., 1995. Borders of multiple visual areas in humans revealed by functional magnetic resonance imaging. Science 268, 889-893.

Shmuel, A., Yacoub, E., Pfeuffer, J., Van de Moortele, P.F., Adriany, G., Hu, X., Ugurbil, K., 2002. Sustained negative BOLD, blood flow and oxygen consumption response and its coupling to the positive response in the human brain. Neuron 36, 1195-1210.

Shmuel, A., Augath, M., Oeltermann, A., Logothetis, N.K., 2006. Negative functional MRI response correlates with decreases in neuronal activity in monkey visual area V1. Nat. Neurosci. 9, 569-577.

Shuwairi, S.M., Curtis, C.E., Johnson, S.P., 2007. Neural substrates of dynamic object occlusion. J. Cogn. Neurosci. 19, 1275-1285.

Slotnick, S.D., 2004. Visual memory and visual perception recruit common neural substrates. Behav. Cogn. Neurosci. Rev. 3, 207-221.

Slotnick, S.D., Schacter, D.L., 2004. A sensory signature that distinguishes true from false memories. Nat. Neurosci. 7, 664-672.

Slotnick, S.D., Schacter, D.L., 2006. The nature of memory related activity in early visual areas. Neuropsychologia 44, 2874-2886.

Slotnick, S.D., Thompson, W.L., Kosslyn, S.M., 2005. Visual mental imagery induces retinotopically organized activation of early visual areas. Cereb. Cortex 15, 1570-1583.

Sterzer, P., Haynes, J.D., Rees, G., 2006. Primary visual cortex activation on the path of apparent motion is mediated by feedback from hMT+/V5. Neurolmage 32, 1308-1316.

Swisher, J.D., Halko, M.A., Merabet, L.B., McMains, S.A., Somers, D.C., 2007. Visual topography of human intraparietal sulcus. J. Neurosci. 27, 5326-5337.

Talairach, J., Tournoux, P, 1988. Co-planar Stereotaxic Atlas of the Human Brain, 3Dimensional Proportional Systems: An Approach to Cerebral Imaging. Thieme Medical Publishers, New York.

Tootell, R.B., Reppas, J.B., Kwong, K.K., Malach, R., Born, R.T., Brady, T.J., Rosen, B.R., Belliveau, J.W., 1995. Functional analysis of human MT and related visual cortical areas using magnetic resonance imaging. J. Neurosci. 15, 3215-3230.

Utter, A.A., Basso, M.A., 2008. The basal ganglia: an overview of circuits and function. Neurosci. Biobehav. Rev. 32, 333-342.

Wandell, B.A., Brewer, A.A., Dougherty, R.F., 2005. Visual field map clusters in human cortex. Philos. Trans. R. Soc. Lond. B Biol. Sci. 360, 693-707.

Watson, J.D., Myers, R., Frackowiak, R.S., Hajnal, J.V., Woods, R.P., Mazziotta, J.C., Shipp, S., Zeki, S., 1993. Area V5 of the human brain: evidence from a combined study using positron emission tomography and magnetic resonance imaging. Cereb. Cortex 3, 79-94. 
Weigelt, S., Singer, W., Muckli, L., 2007. Separate cortical stages in amodal completion revealed by functional magnetic resonance adaptation. BMC Neurosci. 8, 70 .

Wheeler, M.E., Petersen, S.E., Buckner, R.L., 2000. Memory's echo: vivid remembering reactivates sensory-specific cortex. Proc. Natl. Acad. Sci. U. S. A. 97, 11125-11129.
Zeki, S., Watson, J.D., Lueck, C.J., Friston, K.J., Kennard, C., Frackowiak, R.S., 1991. A direct demonstration of functional specialization in human visual cortex. J. Neurosci. 11, 641-649.

Zeki, S., Perry, R.J., Bartels, A., 2003. The processing of kinetic contours in the brain. Cereb. Cortex 13, 189-202. 